\title{
Chromosomal distribution of the 412 retrotransposon in natural populations of Drosophila simulans
}

\author{
C. HOOGLAND, C. VIEIRA \& C. BIÉMONT* \\ Laboratoire de Biométrie, Génétique, Biologie des populations, UMR C.N.R.S. 5558, Université Lyon 1, 69622 \\ Villeurbanne Cedex, France
}

\begin{abstract}
The insertion site localization of the 412 retrotransposable element was analysed by in situ hybridization to the polytene chromosomes of 57 individual genomes from 25 natural populations of Drosophila simulans. The 412 insertion sites along the chromosomes show a tendency to aggregate in the distal and proximal ends of the $2 \mathrm{R}$ arm, and in several local regions along the $3 \mathrm{R}$ arm. The distribution of the 412 insertion sites, weighted by DNA content, along the chromosome arms reveals an overall tendency for the site number to increase from the middle of the arm to the base and tip, with a decrease at the tips, especially pronounced for the $\mathrm{X}$ chromosome. Such a distribution differs slightly from that of D. melanogaster, which globally shows an increase of the 412 site number from base to tip of the chromosome arms, indicating differing behaviour of the 412 element in the two species. These results are discussed in connection with the recombination rate along the chromosome arms.
\end{abstract}

Keywords: chromosomal distribution, Drosophila simulans, natural populations, retrotransposon.

\section{Introduction}

The presence of many transposable elements (TEs) in the genomes of eukaryotes is well established. Their role and the ways in which they are regulated in natural populations, are, however, matters of speculation. From data from Drosophila melanogaster, it is clear that the increase in TE copy number within a genome is mainly counterbalanced by selection acting against either TE insertion mutations or deleterious chromosome rearrangements arising from ectopic exchanges between insertion sites (Charlesworth \& Charlesworth, 1983; Langley et al., 1988; Charlesworth \& Langley, 1989; Stephan \& Langley, 1992). Although some interpretations of the data favour the ectopic exchange model (Charlesworth et al., 1994a,b; Sniegowski \& Charlesworth, 1994; Nuzhdin, 1995), recent results on both $D$. melanogaster and $D$. simulans are more in agreement with selection against insertional mutations (Biémont, 1992; Biémont et al., 1994; Hoogland \& Biémont, 1996; Vieira \& Biémont, 1996a,b). The

\footnotetext{
*Correspondence. E-mail: biemont@biomserv.univ-lyon1.fr
}

main bulk of the data comes from $D$. melanogaster, but it is becoming evident that this species, with its high copy number for most TEs, is not typical of its species group. More knowledge of TE distributions over the chromosome arms in other species is thus necessary, but, so far, only partial data are available, such as the positions of TEs in laboratory stocks, information only of their presence/absence or of their copy numbers, and localizations restricted to the $\mathrm{X}$ chromosomes. Even $D$. simulans, the closest species to D. melanogaster, is not yet well known, although data are now accumulating (Leibovitch et al., 1992; Caggese et al., 1995; Nuzhdin, 1995; Vieira \& Biémont, 1996a,b). Drosophila simulans has a total number of TEs that is about one-third of that in D. melanogaster (Dowsett \& Young, 1982; Csink \& McDonald, 1990; Nuzhdin, 1995; Vieira \& Biémont, 1996a,b), as a result, presumably, of stronger selection against insertions in the $D$. simulans genome than is found in $D$. melanogaster (Nuzhdin, 1995; Vieira \& Biémont, 1996b). For example, the retrotransposable element 412 has a high copy number in both species, but has only half as many copies in $D$. simulans as in $D$. melanogaster. 
Here, we present an analysis of the distribution of this element in the chromosomes in 25 geographically distinct natural populations of $D$. simulans.

\section{Materials and methods}

\section{Drosophila populations}

Flies from 25 geographically distinct, natural population samples of $D$. simulans were used: France $(5$ populations), Portugal (2), Russia (1), Spain (1), Arabia (1), Israel (1), Congo (1), USA (2), Brazil (1), Uruguay (1), Australia (2), New Caledonia (4), Tahiti (1), Madagascar (1) and Réunion (1). They were maintained in the laboratory as isofemale lines with about 50 pairs every generation (see Vieira \& Biémont, 1996a for details). The populations were analysed for their 412 insertion localization as soon as possible after their arrival in the laboratory.

\section{In situ hybridization}

Polytene chromosomes from salivary glands of third instar female larvae were prepared and treated with nick-translated, biotinylated DNA probes, as previously described (Biémont, 1994). Insertion sites were visualized as brown bands resulting from a dye-coupled reaction with peroxidase substrate and diaminobenzidine. We used as probe the 412 element (Finnegan et al., 1978) inserted in pBR322, provided by $\mathrm{N}$. Junakovic. A genomic DNA sequence associated with the probe hybridized to the $21 \mathrm{D}$ region and thus acted as a positive control for hybridization.

\section{Localization of 412 insertion sites}

The localization of the 412 insertion sites was determined on diploid individuals (one larva for two to three isofemale lines analysed directly per population). The sites were precisely localized on the polytene chromosomes following the Lefevre (1976) and Sorsa (1988) photographical maps established for $D$. melanogaster, which are very close to $D$. simulans except for the major inversion $85 \mathrm{~A}-93 \mathrm{~F}$ in the $3 \mathrm{R}$ chromosome arm.

\section{Estimation of DNA content}

The DNA content per division of the polytene chromosomes was estimated following Bolshakov et al. (1985) and Sorsa (1988) using data from $D$. melanogaster. The estimate of Bolshakov measures the number of silver grains in a region after ${ }^{3} \mathrm{H}$-thymidine incorporation. The estimate of Sorsa is based on the number of bands seen in a division, according to the equation: DNA content per chromatid = $\mathrm{LC} \times \mathrm{NB} \times 21.6 \mathrm{~kb}$, where $\mathrm{LC}$ is a coefficient corresponding to the relative length of bands in the division, NB is the number of bands in the division, and $21.6 \mathrm{~kb}$ is the average amount of DNA per band plus adjacent interband.

\section{Statistical tests}

The statistical analyses were based on the number of insertion sites (a site was represented only once per population, even if an insertion at that site was detected in various individuals) rather than on the number of copies; this eliminates any bias caused by high site frequencies resulting from relatedness between individuals or populations, or preferential insertions into specific regions. In all the analyses we excluded the centromeric regions 20, 40-41 and 80-81 because: (i) it is well known that these regions accumulate $\mathrm{TE}$ copies in $\beta$-heterochromatin (Miklos et al., 1988), which is a trap for many nonmobile ancient copies of TEs (Vaury et al., 1989); (ii) although such an accumulation of insertions in the centromeric region is easily seen for the 412 element by in situ hybridization, precise site localization and DNA content estimation in these regions are difficult to obtain and are not reliable.

To analyse the distribution of the 412 insertion sites along the chromosome arms we divided each arm into 120 parts following Bridges's lettered subdivisions. The presence of an insertion site was denoted by 1 and its absence by 0 . The distribution of the $1 \mathrm{~s}$ and $0 \mathrm{~s}$ along the chromosomes was analysed by four nonparametric statistics in which the sites coded 1 were characterized by their ranks in the ordered sequence (see Aulard et al., 1995 for detailed formulae of these statistics). We thus calculated:

1 the sum of ranks of $1(S R)$, which tests the existence of an accumulation of sites at one of the extremities of the chromosome arm;

2 the number of runs (blocks of 0 or 1) (NR), which tests the autocorrelation between sites; a high value of this test detects a regular distribution, a low value suggests partition by blocks;

3 the longest run $(L R)$, which detects a local accumulation of sites;

4 the variance of ranks $(V R)$, which detects aggregation of 1 , either in the middle of the arm (low variance value) or at its two ends (high variance value). The null hypothesis for all these statistics was the random distribution of insertion sites over the chromosomes. 
To analyse the relationship between TE insertion site number and DNA content, the nonparametric Spearman's rank correlation $(\rho)$, with correction in case of ties (Lehmann, 1975), was used because of the non-normality of the data.

\section{Results}

Figure 1 shows the cumulative distributions of the 412 insertion sites along the chromosome arms for the 57 genomes. As revealed by the statistics presented in Table 1, these distributions did not show any significant tendency for the $\mathrm{X}, 2 \mathrm{~L}$ and $3 \mathrm{~L}$ chromosome arms. However, groupings of the 412 insertion sites were detected along the $3 \mathrm{R}$ arm $\left(N R^{\prime}=-3.21, P<0.01\right)$, and an accumulation at both extremities was detected for the $2 \mathrm{R}$ arm $\left(N R^{\prime}=-2.39, P<0.05 ; V R^{\prime}=2.63, P<0.01\right)$. For the statistics that showed the same tendency over the five chromosome arms (Table 1), we calculated:

$U=\left(\Sigma S^{\prime}\right) / \sqrt{5}$

over all arms, which is normally distributed according to the central limit theorem. We thus detected a global aggregation of insertion sites at the two ends of the chromosomal arms $\left(U_{V R^{\prime}}=2.96 ; P<0.01\right)$,

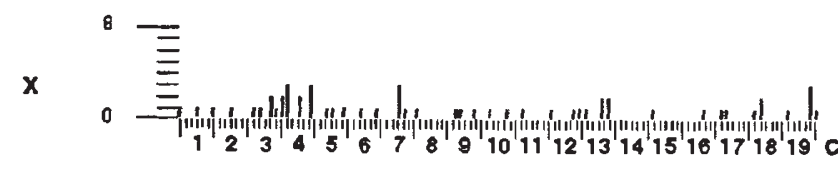

2L

8

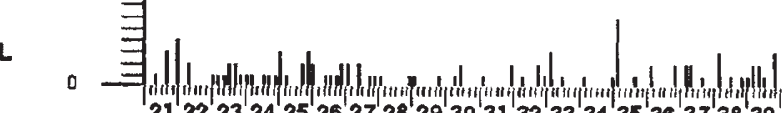
21222324252627282930313233343536373839 c
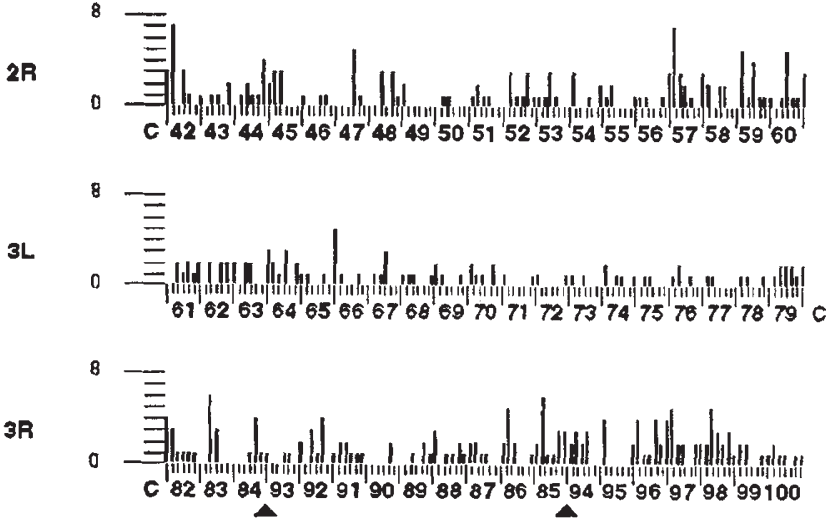

Fig. 1 Localization on the chromosome arms of the 412 retrotransposable element insertion sites found in 57 genomes from 25 populations of Drosophila simulans. C: chromocentre. The inversion $85 \mathrm{~A}-93 \mathrm{~F}$ is marked by arrows. with a more pronounced accumulation at the distal part of the arms $\left(U_{S R^{\prime}}=-2.63 ; P<0.01\right)$.

We have looked for a possible relationship between 412 insertion site number and DNA content along the chromosomes of $D$. simulans, as found previously in $D$. melanogaster for various TEs (Hoogland \& Biémont, 1996). As seen in Table 2,

Table 1 Nonparametric statistics for detecting structure in the distribution of the 412 element insertion sites over the chromosome arms of Drosophila simulans

\begin{tabular}{lrrrrr}
\hline & \multicolumn{5}{c}{ Chromosome arms } \\
\cline { 2 - 6 } Statistics & $\mathrm{X}$ & $2 \mathrm{~L}$ & $2 \mathrm{R}$ & $3 \mathrm{~L}$ & \multicolumn{1}{c}{$3 \mathrm{R}$} \\
\hline & $(43)$ & $(62)$ & $(70)$ & $(62)$ & $(79)$ \\
$S R^{\prime}$ & -1.46 & -0.84 & -1.05 & -0.77 & -1.76 \\
$N R^{\prime}$ & 0.09 & 0.46 & $-2.39^{*}$ & 0.08 & $-3.21^{* *}$ \\
$L R$ & 0.74 & 0.28 & 0.36 & 0.90 & 0.40 \\
$V R^{\prime}$ & 0.31 & 1.53 & $2.63^{* *}$ & 1.52 & 0.62 \\
\hline
\end{tabular}

$S R$ : sum of ranks; $N R$ : number of runs; $L R$ : longest run; $V R$ : variance of ranks (see text for details).

For all statistics, but $L R$, we calculated the normal approximation because the observed number of insertion sites was greater than or equal to 10 . The statistic with a prime:

$S^{\prime}=\frac{S_{\mathrm{obs}}-\mathrm{E}(S)}{\sqrt{\operatorname{Var}(S)}}$

is normally distributed. $S_{\text {obs }}$ is the observed value, $\mathrm{E}(S)$ and $\operatorname{Var}(S)$, respectively, the mean and variance of the statistic $S$. For the $L R$ statistic, the exact probability is given.

The numbers of insertion sites observed are in parentheses.

${ }^{*} P<0.05 ;{ }^{*} P<<0.01$.

Table 2 Spearman's rank correlation coefficients for 412 insertion site number versus DNA content (Sorsa and Bolshakov estimations) in Drosophila simulans

\begin{tabular}{llc}
\hline $\begin{array}{l}\text { Chromosome } \\
\text { arms }\end{array}$ & \multicolumn{2}{c}{ DNA content estimation } \\
\hline X & Sorsa & Bolshakov \\
2L & $0.50^{*}$ & $0.51^{*}$ \\
2R & 0.18 & 0.27 \\
3L & 0.18 & 0.17 \\
3R & $0.47^{*}$ & $0.57^{* *}$ \\
\hline
\end{tabular}

* One-tailed $P<0.05 ;{ }^{* *}$ one-tailed $P<0.01$.

(c) The Genetical Society of Great Britain, Heredity, 79, 128-134. 
the two variables are significantly correlated for the $\mathrm{X}$ and $3 \mathrm{~L}$ arms using both the Bolshakov and the Sorsa estimates of DNA content. We thus divided the number of 412 insertion sites in each of Bridges's divisions by the DNA content in the division. Figure 2 thus represents the distribution in each chromosome arm of the number of 412 insertion sites weighted by DNA content. In agreement with the above results on the insertion site distribution along the chromosomes, there was a global tendency for 412 insertion site number to decrease from the tip and base to the middle of the chromosomal arms, with a decrease at the extreme tip of chromosomes, especially for the X (Fig. 2).

To see whether the above result was specific to $D$. simulans or whether it is also seen in D. melanogaster, we used the insertion sites of 412 in $D$. melanogaster available in the literature. We pooled the data from a French population, Valence (185 insertion sites: Aulard et al., 1995), and a Maryland population (165 insertion sites: Charlesworth \& Lapid, 1989; Charlesworth et al., 1992a). Figure 3 represents the distribution of 412 insertion site number weighted by DNA content along an average chromosome (the five arms are superimposed) for each species. It appears that $D$. melanogaster differs from $D$. simulans by a less pronounced accumulation of 412 insertions in specific regions, and with the number of 412 insertions clearly increasing from the base to the tip of the average chromosome. In contrast, on average, the 412 insertion site number in $D$. simulans decreases from the tip and the base to the middle of the chromosome arms, with a sharp decrease at the tip especially caused by the $\mathrm{X}$ chromosome. The chi-squared values calculated on each chromosome arm from data on insertion site numbers weighted by Bolshakov DNA content estimate per division have been summed to test the difference between the distributions observed in the two species. There is no significant difference in the two average distributions $\left(\chi_{90}^{2}=100.5 ; P=0.21\right)$, but a significant difference between the two distributions on the $\mathrm{X}$ chromosome is found $\left(\chi_{18}^{2}=32.96\right.$; $P<0.05)$. However, the two sets of data were not entirely comparable because with $D$. simulans we were dealing with few individuals from many various populations, whereas the $D$. melanogaster data concerned many individuals in only two populations. More data on various $D$. melanogaster populations are thus needed to confirm these latter results.
Fig. 2 Distribution per Bridges's division of the 412 insertion site number weighted by DNA content from Bolshakov along the five chromosome arms of Drosophila simulans. The inversion $85 \mathrm{~A}-93 \mathrm{~F}$ is marked by arrows.

Because the Bolshakov and Sorsa estimators of DNA content give similar distributions of DNA content along the chromosome arms (Hoogland and Biémont, 1996), only data from the Bolshakov estimate were used.
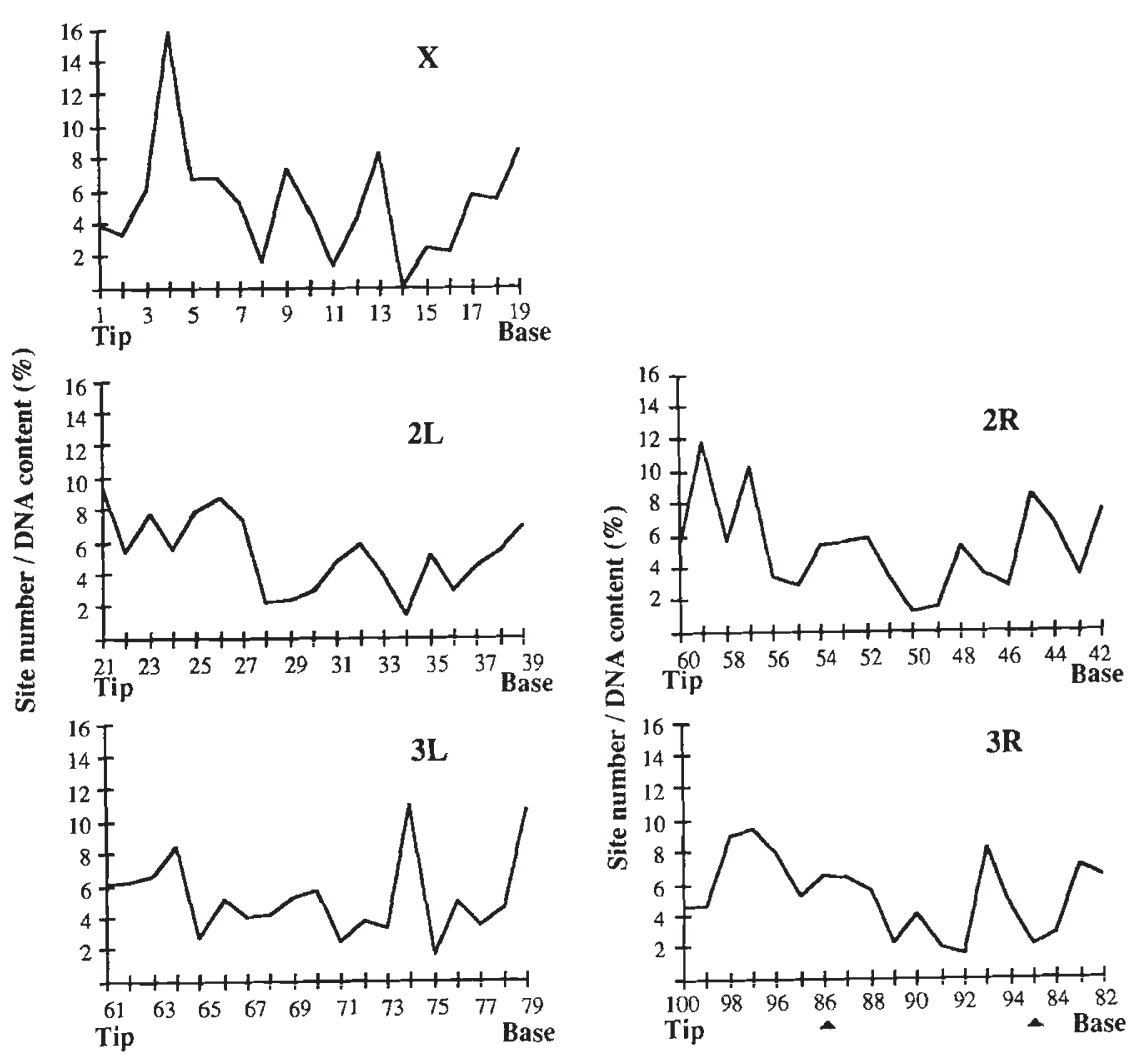

(c) The Genetical Society of Great Britain, Heredity, 79, 128-134. 


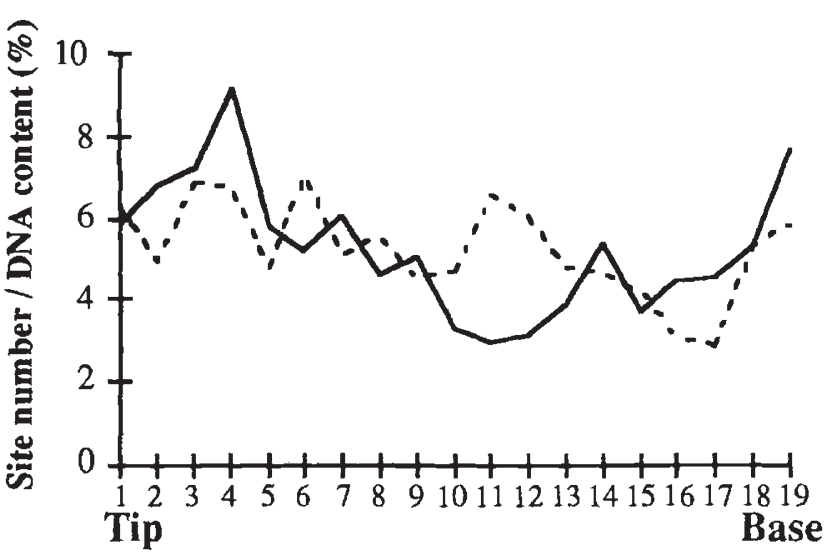

Fig. 3 Distribution along the 19 divisions of an average chromosome arm (the five arms are superimposed) of the relative (in \%) 412 insertion site number weighted by DNA content (Bolshakov estimation: see Fig. 2) in Drosophila simulans (solid line) and in Drosophila melanogaster (dashed line).

\section{Discussion}

The distribution of TE insertion sites in the chromosomes is of interest in testing models of TE population dynamics. These models postulate that TE copy number is maintained in populations as a result of a balance between transposition, which increases the number of copies, and opposing forces, which tend to reduce it. Such opposing forces include regulation of transposition rate with increasing copy number (Charlesworth \& Charlesworth, 1983; Kaplan \& Brookfield, 1983; Langley et al., 1983), selection against insertional mutations (Charlesworth \& Charlesworth, 1983; Kaplan \& Brookfield, 1983; Langley et al., 1983; Kaplan et al., 1985; Montgomery et al., 1987), and selection against deleterious chromosome arrangements induced by ectopic exchanges between TEs (Langley et al., 1988; Stephan \& Langley, 1992). Ectopic exchanges are sometimes presented as the main factor explaining the dynamics of TEs (Langley et al., 1988; Charlesworth et al., 1992b, 1994b; Sniegowski \& Charlesworth, 1994; Nuzhdin, 1995). In this model, TE site number is negatively correlated with recombination rate, assuming that the frequency of ectopic exchanges in a region is proportional to meiotic exchanges in that region (Langley et al., 1988). To test this hypothesis, authors usually check whether TE insertions accumulate in regions where crossing-over is strongly reduced, such as the bases and tips of the $D$. melanogaster polytene chromosomes (Lindsley \& Sandler, 1977). In this species, experimental data available for a survey of $10 \mathrm{TE}$ families (including 412) failed to show an accumulation of TE insertion sites at the tips of the chromosome (Langley et al., 1988; Charlesworth \& Lapid, 1989; Charlesworth et $a l ., 1992 b)$, and there is no consensus for accumulation at the bases, because this depends on whether the centromeric and pericentromeric regions of the chromosomes are included (these are known to be traps for nonmobile ancient copies of TEs; Miklos et al., 1988; Vaury et al., 1989). Indeed when TEs inserted in centromeric and pericentromeric regions are excluded from the data, no simple relationship between insertion site number and recombination rate can be detected in $D$. melanogaster (Biémont et al., 1994; Hoogland \& Biémont, 1996). The fact that the 412 element in $D$. melanogaster has never been shown to accumulate in the bases of the autosomes (Charlesworth et al., 1992b; Aulard et al., 1995) may thus rely on the absence of fixed sites of 412 in these proximal regions.

Our data on the distribution of 412 insertions in $D$. simulans reveal an overall tendency for site number to decrease from the tip and the base to the middle of the chromosomal arms, with a sharp decrease at the extreme tips, especially for the $\mathrm{X}$ chromosome. One way to test the ectopic exchange model of TE site number containment in $D$. simulans consists of correlating the distribution of 412 insertion site number with the recombination rate along the chromosomes. Unfortunately, we have not yet a complete view of the frequency and distribution of crossovers in $D$. simulans, whose total genetic map length is 1.3 times longer than the $D$. melanogaster map (Ashburner, 1989; True et al., 1996). The $\mathrm{X}$ chromosome seems to have the same distribution of recombination rate as $D$. melanogaster, which increases from base to tip with a sharp decrease at the extreme tip (Lindsley \& Sandler, 1977; True et al., 1996), suggesting an absence of association between recombination rate and 412 insertion site number in $D$. simulans for this chromosome. The coefficient of exchange value in the third chromosome, which is higher than in D. melanogaster, increases from base and tip to the middle of each arm (True et al., 1996). It is thus tempting to conclude that the 412 insertion site number, which decreases from tip and base to the middle of each arm of this third chromosome, was negatively correlated with the recombination rate, in agreement with the ectopic exchange model (Langley et al., 1988; Charlesworth et al., 1992b, 1994b; Stephan \& Langley, 1992; Sniegowski \& Charlesworth, 1994). We have no information on the coefficient of exchange for the $2 \mathrm{~L}$ and $2 \mathrm{R}$ arms in which the 412 insertion site number evidently increased toward the bases and tips. More information on recombination 
rates in $D$. simulans is clearly needed to address properly the question of a relationship between recombination rate and TE chromosomal distribution in this species.

There is little evidence, however, that the 412 insertion site distribution in $D$. simulans differs from that of $D$. melanogaster, at least for the X chromosome. If these two siblings species are submitted to the same evolutionary forces, it is not obvious why the 412 element behaves differently. These data on the 412 element, conjointly with other studies in $D$. simulans (Vaury et al., 1989; Leibovitch et al., 1992; Kimura \& Kidwell, 1994; Caggese et al., 1995; Nuzhdin, 1995; Vieira \& Biémont, 1996b), reinforce the hypothesis of specific TE behaviours, depending on the TE family and the host species.

\section{Acknowledgements}

We are grateful to B. Charlesworth for his data on 412 insertion sites in the Maryland population. We thank C. Arnault, C. Gautier and the two referees for their comments. This work was supported by the Centre National de la Recherche Scientifique (UMR 5558), the Ministère de la Recherche, the Junta Nacional de Investigaçao Cientifica (Portugal), and the Association pour la Recherche sur le Cancer (contract 6251 to C.B.).

\section{References}

ASHBURner, M. 1989. Drosophila. A Laboratory Handbook. Cold Spring Harbor Laboratory Press, New York.

AULARD, S., LEMEUNIER, F., HOOGLAND, C., CHAMINADE, N., BROOKFIELD, J. F. AND BIÉMONT, C. 1995. Chromosomal distribution and population dynamics of the 412 retrotransposon in a natural population of Drosophila melanogaster. Chromosoma, 103, 693-699.

BIÉMONT, C. 1992. Population genetics of transposable DNA elements. A Drosophila point of view. Genetica, 86, 67-84.

BIÉMONT, C. 1994. Dynamic equilibrium between insertion and excision of $\mathrm{P}$ elements in highly inbred lines from an $\mathrm{M}^{\prime}$ strain of Drosophila melanogaster. J. Mol. Evol., 39, 466-472.

BiÉmONT, C., Lemeunier, F., Garcia GUeRreiro, M. P., BROOKFIELD, J. F., GAUTIER, C., AULARD, S. AND PASYUKOVA, E. G. 1994. Population dynamics of the copia, mdg1, mdg3, gypsy, and $P$ transposable elements in a natural population of Drosophila melanogaster. Genet. Res., 63, 197-212.

BOLSHAKOV, V. N., ZHARKIKH, A. A. AND ZHIMULEV, 1. F. 1985. Intercalary heterochromatin in Drosophila. II. Heterochromatic features in relation to local DNA content along the polytene chromosomes of Drosophila melanogaster. Chromosoma, 92, 200-208.
CAGGeSE, C., PIMPINElli, S., BARSANTI, P. AND CAIZZI, R. 1995. The distribution of the transposable element Bari1 in the Drosophila melanogaster and Drosophla simulans genomes. Genetica, 96, 269-283.

CHARLESWORTH, B. AND CHARLESWOTH, D. 1983. The population dynamics of transposable elements. Genet. Res., 42, 1-27.

CHARLESWORTH, B. AND LANGley, C. H. 1989. The population genetics of Drosophila transposable elements. Ann. Rev. Genet., 23, 251-287.

CHARLESWORTH, B. AND LAPID, A. 1989. A study of 10 transposable elements on $\mathrm{X}$ chromosomes from a population of Drosophila melanogaster. Genet. Res., 54, $113-125$.

CHARLESWORTH, B., LAPID, A. AND CANADA, D. 1992a. The distribution of transposable elements within and between chromosomes in a population of Drosophila melanogaster. I. Element frequencies and distribution. Genet. Res., 60, 103-114.

CHARLESWORTH, B., LAPID, A. AND CANADA, D. 1992b. The distribution of transposable elements within and between chromosomes in a population of Drosophila melanogster. II. Inferences on the nature of selection against elements. Genet. Res., 60, 115-130.

CHARLESWORTH, B., JARNE, P. AND ASSIMACOPOUlOS, S. 1994a. The distribution of transposable elements within and between chromosomes in a population of Drosophila melanogaster. III. Element abundances in heterochromatin. Genet. Res., 64, 183-197.

CHARLESWORTH, B., SNIEGOWSKI, P. AND STEPHAN, W. 1994b. The evolutionary dynamics of repetitive DNA in eukaryotes. Nature, 371, 215-220.

CSINK, A. K. AND MCDONALD, J. F. 1990. Copia expression is variable among natural populations of Drosophila. Genetics, 126, 375-385.

DOWSETT, A. P. AND YOUNG, M. w. 1982. Differing levels of dispersed repetitive DNA among closely related species of Drosophila. Proc. Natl. Acad. Sci. U.S.A., 79, 4570-4574.

FINNEGAN, D. J., RUBIN, G. M., YOUNG, M. W. AND HOGNESS, D. C. 1978. Repeated gene families in Drosophila melanogaster. Cold Spring Harbor Symp. Quant. Biol., 42, 1053-1064.

HOOGLAND, C. AND BIÉMONT, C. 1996. Chromosomal distribution of transposable elements in Drosophila melanogaster: test of the ectopic recombination model for maintenance of insertion site number. Genetics, 144, 197-204.

KAPLAN, N. L. AND BROOKFIELD,J. F. Y. 1983. Transposable elements in Mendelian populations. III. Statistical results. Genetics, 104, 485-495.

KAPLAN, N. L., DARDEN, T. AND LANGLEY, C. H. 1985. Evolution and extinction of transposable elements in Mendelian populations. Genetics, 109, 459-480.

KIMURA, K. AND KIDWELL, M. G. 1994. Differences in P element population dynamics between the sibling species Drosophila melanogaster and Drosophila simulans. Genet. Res., 63, 27-38. 
LANGLEY, C. H., BROOKFIELD, J. F. Y. AND KAPLAN, N. 1983. Transposable elements in Mendelian populations. I. A theory. Genetics, 104, 457-472.

LANGLEY, C. H., MONTGOMERY, E. A., HUDSON, R., KAPLAN, N. AND CHARLESWORTH, B. 1988. On the role of unequal exchange in the containment of transposable element copy number. Genet. Res., 52, 223-235.

LEFEVRE, G. 1976. A photographic representation and interpretation of polytene chromosomes of Drosophila melanogaster salivary glands. In: Ashburner, M. and Novitski, E. (eds) The Genetics and Biology of Drosophila, 1A, pp. 31-66. Academic Press, London.

LeHmanN, E. L. 1975. Nonparametrics Statistical Methods Based on Ranks. McGraw Hill, New York.

LeIbovitch, B. A. GLUSHKOVA, I. V., PASYUKOVA, E. G., Belyaeva, E. S. AND GVOzdeV, v. A. 1992. Comparative analysis of retrotransposon localization and mobility in sibling species Drosophila simulans and Drosophila melanogaster. Genetika, 28, 85-97.

LINDSLEY, D. L. AND SANDLER, L. 1977. The genetic analysis of meiosis in female Drosophila melanogaster. Phil. Trans. R. Soc. B, 277, 295-312.

Miklos, G. L. G., YAMAMOTO, M. T., DAVIES, J. AND PIRROTTA, V. 1988. Microcloning reveals a high frequency of repetitive sequences characteristic of chromosome 4 and the $\beta$-heterochromatin of Drosophila melanogaster. Proc. Natl. Acad. Sci. U.S.A., 85, 2051-2055.

MONTGOMERY, E. A., CHARLESWORTH, B. AND LANGLEY, C. H. 1987. A test for the role of natural selection in the stabilization of transposable element copy number in a population of Drosophila melanogaster. Genet. Res., 49, 31-41.

NUZHDIN, s. V. 1995. The distribution of transposable elements on $\mathrm{X}$ chromosomes from a natural population of Drosophila simulans. Genet. Res., 66, 159-166.

SNIEGOWSKI, P. AND CHARLESWORTH, B. 1984. Transposable element numbers in cosmopolitan inversions from a natural population of Drosophila melanogaster. Genetics, 137, 815-827.

SORSA, v. 1988. Chromosome maps of Drosophila, vol. II. CRC Press Inc., Boca Raton, FL.

STEPHAN, W. AND LANGLEY, C. H. 1992. Evolutionary consequences of DNA mismatch inhibited repair opportunity. Genetics, 132, 567-574.

TRUe, J. R., MERCER, J. M. AND LAURIE, C. C. 1996. Differences in crossover frequency and distribution among three sibling species of Drosophila. Genetics, 142, 507-523.

VAURY, C., BUCHETON, A. AND PELISSON, A. 1989. The $\beta$-heterochromatic sequences flanking the I elements are themselves defective transposable elements. Chromosoma, 98, 215-224.

VIEIRA, C. AND BIÉMONT, C. 1996a. Geographical variation in insertion site number of retrotransposon 412 in Drosophila simulans. J. Mol. Evol., 42, 443-451.

VIEIRA, C. AND BIÉMONT, C. 1996b. Selection against transposable element insertions in $D$. simulans and $D$. melanogaster. Genet. Res., 68, 9-15. 